\title{
Methodology for the Integration of Information, Communication and Automation Technologies in Housing Rehabilitation
}

\author{
Sara Eloy ${ }^{12}$, Renato Nunes ${ }^{1}$, Isabel Plácido ${ }^{2}$, José Pinto Duarte ${ }^{1}$ \\ ${ }^{1}$ Technical University Lisbon, ${ }^{2}$ National Laboratory for Civil Engineering \\ Lisbon, Portgal \\ sara.eloy@iscte.pt, renato.nunes@ist.utl.pt, iplacido@Inec.pt, jduarte@fa.utl.pt
}

\begin{abstract}
This paper addresses the integration of Information, Communication and Automation Technologies (ICAT) in the dwelling space in order to meet the user's needs. We describe an ongoing $\mathrm{PhD}$ research which deals with the rehabilitation of the existing housing stock in order to fulfil the new needs of dwellers in the current Information Society as well as the impact of the integration of ICAT in dwellings. For this purpose we establish a rehabilitation methodology which enables architects to fulfil the client's needs and requirements in home automation, from the beginning of the architectural process. This will enable the creation of a compatible and properly integrated ICAT infrastructure in homes, paving the way for ambient intelligence and promoting sustainable strategies at the environmental and social levels.
\end{abstract}

Keywords: Information, communication and automation technologies, housing, rehabilitation.

\section{Introduction}

With this research we are dealing with two fundamental problems: the urgency of rehabilitating the existing housing stock and the urgency of integrating ICAT in homes.

Much of the existing housing stock in Lisbon needs rehabilitation due to both constructive pathologies as well as to emergent conflicts in the use of spaces that result from changes in current lifestyles. New approaches to the design of domestic spaces will answer theses demands and meet the need for accommodating activities such as telework and telehealth, in response to the growing demand of information access, comfort and safety in homes. The first research goal is to identify how the use of technology influences the ways of living and creates new dwelling requirements, and how this impacts the spatial and functional organization of dwellings. This work complements Pedro's (2000) and Duarte's (2001) frameworks and Oliveira's research (2000) to incorporate new dwelling modes, new compositions of domestic groups, and ICAT-related demands. The integration of ICAT in housing is a priority in the quest for improved housing quality, comfort and adaptability. ICAT also promotes ecological sustainability as well as social sustainability by promoting social

The original publication is available at www.springerlink.com

Eloy, S.; Nunes, R.; Plácido, I.; Duarte, J.P.; Methodology for the Integration of Information, Communication and Automation Technologies in Housing Rehabilitation in Augusto, J.C.; Corchado, J.M.; Novais, P.; Analide, C. (editors), Proceedings of the ISAmI 2010: International Symposium on Ambient Intelligence, Universidade do Minho, Guimarães, Portugal, June 16-18, 2010 Advances in Intelligent and Soft Computing 72. Springer, 2010. pp. 221-228. 
inclusion of citizens and supporting the elderly and people with reduced mobility. Besides the advantages of domotics in assisting the elderly and disabled persons, these technologies assist all people in their daily tasks, making everyone's life more comfortable and safe. Considering the importance of providing ICAT in houses, one of the fundamental goals of the ongoing research is the definition of adequate sets of ICAT to incorporate in the dwelling spaces according to family profiles. The provision of such technologies aims at guaranteeing sustainability and the social integration of citizens, while adapting them to each household, according to its present and future needs. Such set of ICAT would be applicable to the dwelling as well as the building, not only in new construction but also in the rehabilitation of the existing residential stock. The last goal of this research is to define design guidelines, as well as a methodology, to support architects in the adaptation of existing dwellings and in the incorporation of ICAT while allowing them to balance new dwelling trends with sustainable requirements and economic feasibility.

This paper will focus on both the definition of adequate sets of ICAT according to family profiles as well as the proposed methodology for integrating them in housing rehabilitation.

\section{ICAT as ecological and social sustainability strategies}

Home automation systems can have a very important role in contemporary dwellings because of the benefits they bring to residents both regarding ecological and social aspects. Domotics represents a means to manage household energy use and to complement, not to substitute, passive solutions. A well insulated building is the most effective element of an efficient heating, ventilating, and air conditioning (HVAC) system. Therefore, automated domotic controls for HVAC systems represent a complement to the passive strategy. The often called "Smart House" will only be smart if, additionally to automation controls, it is designed and built in a sustainable way. This means environmentally-conscious design techniques in the field of architecture using efficient insulation, earth friendly building materials, energy and water conservation, solar energy, wind-power, among other strategies. However, when actuating over existing buildings the achievement of efficient passive solutions often fails due to morphological and construction restrains. In such cases, where passive solutions prove to be insufficient, active systems are required to increase comfort standards. Better control systems for heating and cooling management are fundamental to achieve that goal and promote energy efficiency. There are several domestic automation solutions that can be used for cutting energy consumption, including presence detection devices, solar control systems (intelligent control of blinds and other protective shades that can be lowered, raised and tilted according to the detected location of the sun), and computer controlled ventilation by motorized opening of doors and windows. 
In addition to promoting ecological sustainability, ICAT helps improving the lives of inhabitants as it can anticipate and respond to resident's demands, thereby promoting social sustainability. Smart houses can also serve the elderly and people with reduced mobility, as well as other groups of inhabitants, assuring their comfort and contributing to their safety, by allowing them to surpass obstacles and supporting the execution of their daily tasks. Assistive technologies can be designed to evolve as the resident requires more assistance around the home and helps them living more independently.

\section{Defining the methodology}

Ongoing research intends to define a rehabilitation methodology for Lisbon's existing housing stock so that it responds to new technology requirements and new ways of living. Our work started with the analysis of dwellers demands as well as with the development of a knowledge base regarding the set of existing ICAT for homes, which will be taken into account during the application of the rehabilitation methodology. Then we raised a hypothesis for such a methodology which should encompass four steps, as shown in Fig. 1.

The first step consists in gathering the data needed for the rehabilitation process: the profile of the future dwellers and a description of the existing dwelling. In the second step the family profile is used to elaborate the ideal functional program of the dwelling as well as the ideal pack of ICAT functions. The ideal pack of ICAT functions is a description of an ideal set of systems and functions that respond to a given family profile. This pack of ICAT is not bound to any existing morphological or construction restrains. Similarly, the ideal functional program is a description of the ideal housing solution for that family regarding spaces, rooms and topology relations between them. In the third step, the existing dwelling and both the ideal functional program and the ideal pack of ICAT, are used to derive a description of a compromised or adapted solution based on the existing dwelling. Since the solution is conditioned by the existing morphological structure, a third step is necessary to transform the description of an ideal solution into the description of an adapted one.

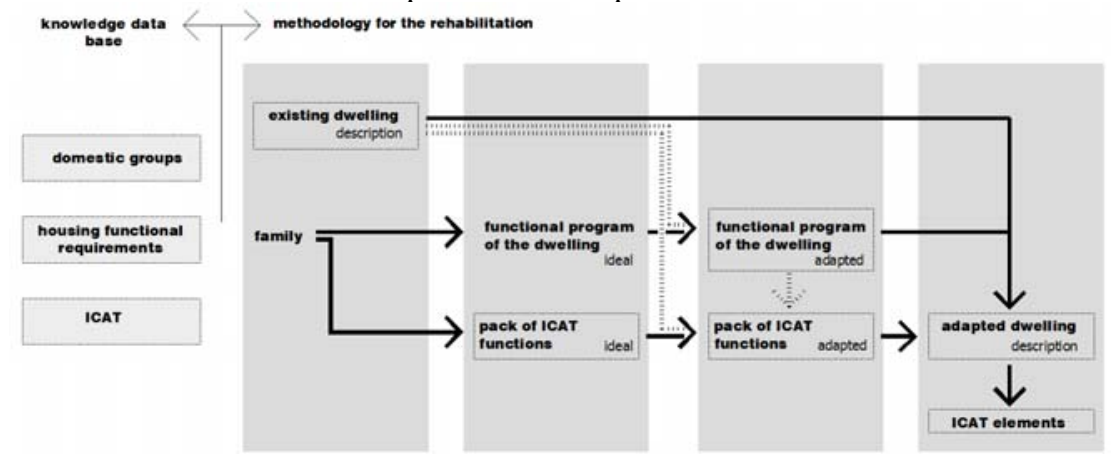

Fig. 1. Basic steps in the envisioned rehabilitation methodology. 
Finally, from the description of the adapted dwelling is obtained the layout of a design solution for that family in that dwelling, which includes the ICAT components needed in the dwelling. For the purpose of incorporating ICAT in dwellings two complementary methods were established. First, the introduction of ICAT in dwellings changes some aspects of living (e.g. home cinema, telework) which were taken into account in the definition of today's houses functions. Second, the introduction of ICAT in dwellings operates physical changes in the house prompted by the need for accommodating cabling infrastructures and terminal equipment.

\section{Packs of ICAT functions}

Smart homes should address the inhabitant's demands and needs. However there is frequently a gap between the implemented technology and user's real needs. This gap occurs because the implementation of home automation is usually undertaken without previous knowledge of end-users (e.g. in multi-family residential buildings) or without understanding the exact needs of residents (). It is important that every stakeholder within the building process, in particular the architects and clients, have enough knowledge of ICAT so that the pack of technologies chosen can be used in a useful way by the end-user.

To achieve the definition of the ideal pack of ICAT functions we considered several types of households and, based on their characteristics and anticipated needs and activities within the home, we establish a set of essential domotic functions. This method follows previous works on: i) user-centered approach by Meyer and Schulze (1996) on uptake of technology based on household characteristics; Bierhoff and Berlo (2007), on technology preferences based on lifestyles; Becker and Van de Goor (2002) on technology generation; ii) centered approach on activities which take place at home by Mateas et al. (1996), iii) hierarchical classes of smart home by Aldrich (2003).

For each family profile we defined three levels of ICAT packs that can be chosen according to the family's economic capacity. The minimal proposed level of ICAT is recommended to every new or rehabilitated house or dwelling. This level includes wired infra-structures, basic security systems and access to ICT, and the exact definition of these features varies slightly according to different family's profiles. This minimum level contains all cable infra-structure needed to allow upgrading the system up to the optimal level. The minimum level is suitable for low budgets households and property developers who want to make a small investment without compromising the upgradability of the system. The medium level is an upgrade of the lower level and it requires a greater financial investment. This level includes automation technologies that go beyond the basic setup. The optimum level of ICAT integrates a complete set of technologies for the prospective family needs, without becoming unreasonable. A simplified version of the assignment of ICAT functions according to family profiles is shown in Table 1 considering the above mentioned levels of integration. We classified families based on their kinship, age and number. 
Table 1. Assignment of ICAT functions according to family profile.

\begin{tabular}{|c|c|c|c|c|c|c|c|c|c|c|c|c|c|c|c|c|c|}
\hline & \multicolumn{4}{|c|}{$\begin{array}{l}\text { Couple with } \\
\text { children }\end{array}$} & \multicolumn{4}{|c|}{$\begin{array}{l}\text { Couple } \\
\text { without } \\
\text { children }\end{array}$} & \multicolumn{4}{|c|}{$\begin{array}{l}\text { Monoparen- } \\
\text { tal families }\end{array}$} & \multicolumn{2}{|c|}{$\begin{array}{l}\text { Co- } \\
\text { habitat } \\
\text { ion }\end{array}$} & \multicolumn{3}{|c|}{$\begin{array}{l}1 \text { house- } \\
\text { hold }\end{array}$} \\
\hline $\begin{array}{l}\text { Home automation } \\
\text { functions }\end{array}$ & 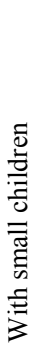 & $\begin{array}{l}\overline{0} \\
\frac{0}{7} \\
3 \\
0 \\
3 \\
3 \\
0 \\
50 \\
5 \\
5 \\
5\end{array}$ & 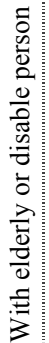 & 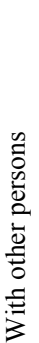 & 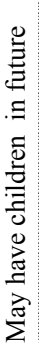 & $\begin{array}{l}0 \\
.0 \\
0 \\
0 \\
0 \\
0 \\
0 \\
0 \\
0 \\
0 \\
0 \\
0 \\
0 \\
0 \\
0 \\
0 \\
0 \\
0 \\
0\end{array}$ & 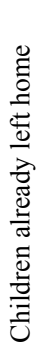 & 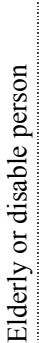 & 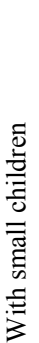 & 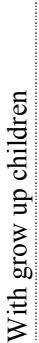 & 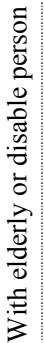 & 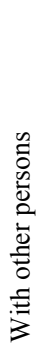 & 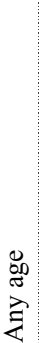 & 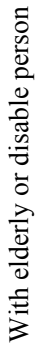 & $\stackrel{\infty}{\Xi}$ & 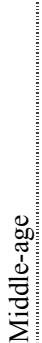 & 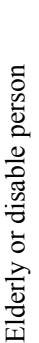 \\
\hline
\end{tabular}

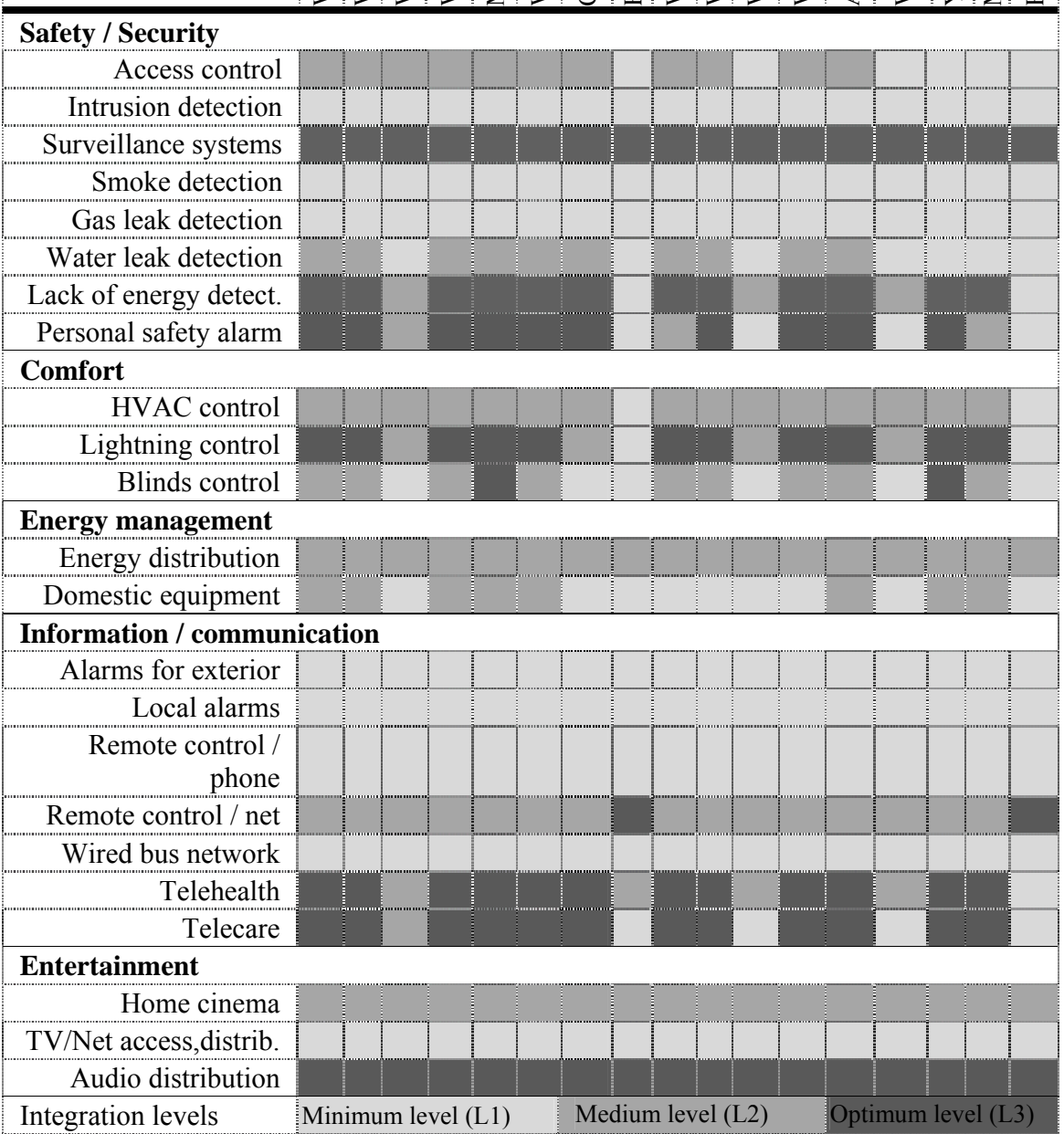

The original publication is available at www.springerlink.com

Eloy, S.; Nunes, R.; Plácido, I.; Duarte, J.P.; Methodology for the Integration of Information, Communication and Automation Technologies in Housing Rehabilitation in Augusto, J.C.; Corchado, J.M.; Novais, P.; Analide, C. (editors), Proceedings of the ISAmI 2010: International Symposium on Ambient Intelligence, Universidade do Minho, Guimarães, Portugal, October 13-15, 2010. Advances in Intelligent and Soft Computing 72. Springer, 2010. pp. 221-228. 
We added a class for elderly and disabled people to each one of the previous classes, so that a household with a disabled person incorporates assistive technologies. The pack of assistive technologies is not shown in this paper.

In addition to the pack of ICAT we defined construction strategies to incorporate domotic appliances as well as wire and wireless infra-structures in a rehabilitation work. These strategies take into account that by intervening in an existing building, rehabilitation requires one to manage different construction techniques and cabling demands. Simultaneously, one needs to ensure space flexibility considering both present and future needs. The proposed methodology aims at defining the adequate set of ICAT functions and their integration following the four steps described earlier and illustrated in Fig. 1.

\section{Methodology application - an example}

Adapting the dwelling to the family's needs according to the new functional program and ICAT pack, involves a series of steps. We have defined three different rehabilitation strategies accordingly to the spatial transformation of the dwelling. In the current research, we are using what we call a transformation grammar which will allow us to transform an existing design into a new one that matches given requirements. Transformation grammars drift from shape grammars whose investigation started more than thirty years ago with Stiny and Gips (1972). Shape grammars are algorithmic systems with a set of rules that apply to shapes in a step-by-step way to generate a language of designs.

Table 2. Steps to follow in the adaption of a dwelling.

\begin{tabular}{|c|c|c|c|}
\hline steps & Spatial transformation & & Incorporation of ICAT elements \\
\hline 0 & $\begin{array}{l}\text { Locate social and private } \\
\text { areas }\end{array}$ & \multirow[t]{2}{*}{7} & \multirow{2}{*}{$\begin{array}{l}\text { Define consumers: } 7.1 \text { sensors (water, } \\
\text { motion, temperature, smoke, light); } 7.2 \\
\text { controlled lights and power sockets; } 7.3 \\
\text { controlled motor blinds; } 7.4 \text { electric } \\
\text { valves, } 7.5 \text { electric oven, } 7.6 \ldots\end{array}$} \\
\hline 1 & $\begin{array}{l}\text { If functional program has } \\
2 \text { or more bedrooms } \rightarrow \\
\text { define private area }\end{array}$ & & \\
\hline 2 & $\begin{array}{l}\text { If functional program has } \\
2 \text { or more bedrooms } \rightarrow \\
\text { define social area }\end{array}$ & 8 & $\begin{array}{l}\text { Define operating points: } 8.1 \text { control } \\
\text { panels; } 8.2 \text { push buttons }\end{array}$ \\
\hline 3 & $\begin{array}{l}\text { Resolve circulation (social } \\
\text { and private area) }\end{array}$ & 9 & Define network (diagram) \\
\hline 4 & Define service area & 10 & Create a consumer list \\
\hline 5 & Define storage spaces & 11 & Create a list of operating points \\
\hline 6 & $\begin{array}{l}\text { Resolve circulation } \\
\text { between different } \\
\text { circulation spaces }\end{array}$ & & \\
\hline
\end{tabular}


The list of steps to follow in the rehabilitation according to one of the rehabilitation strategies is systematized in Table 2 . Due to space limitations, in this paper we only show a sample of the spatial transformation and the integration of ICAT in order to illustrate how the grammar works and can be applied - see Fig. 2.

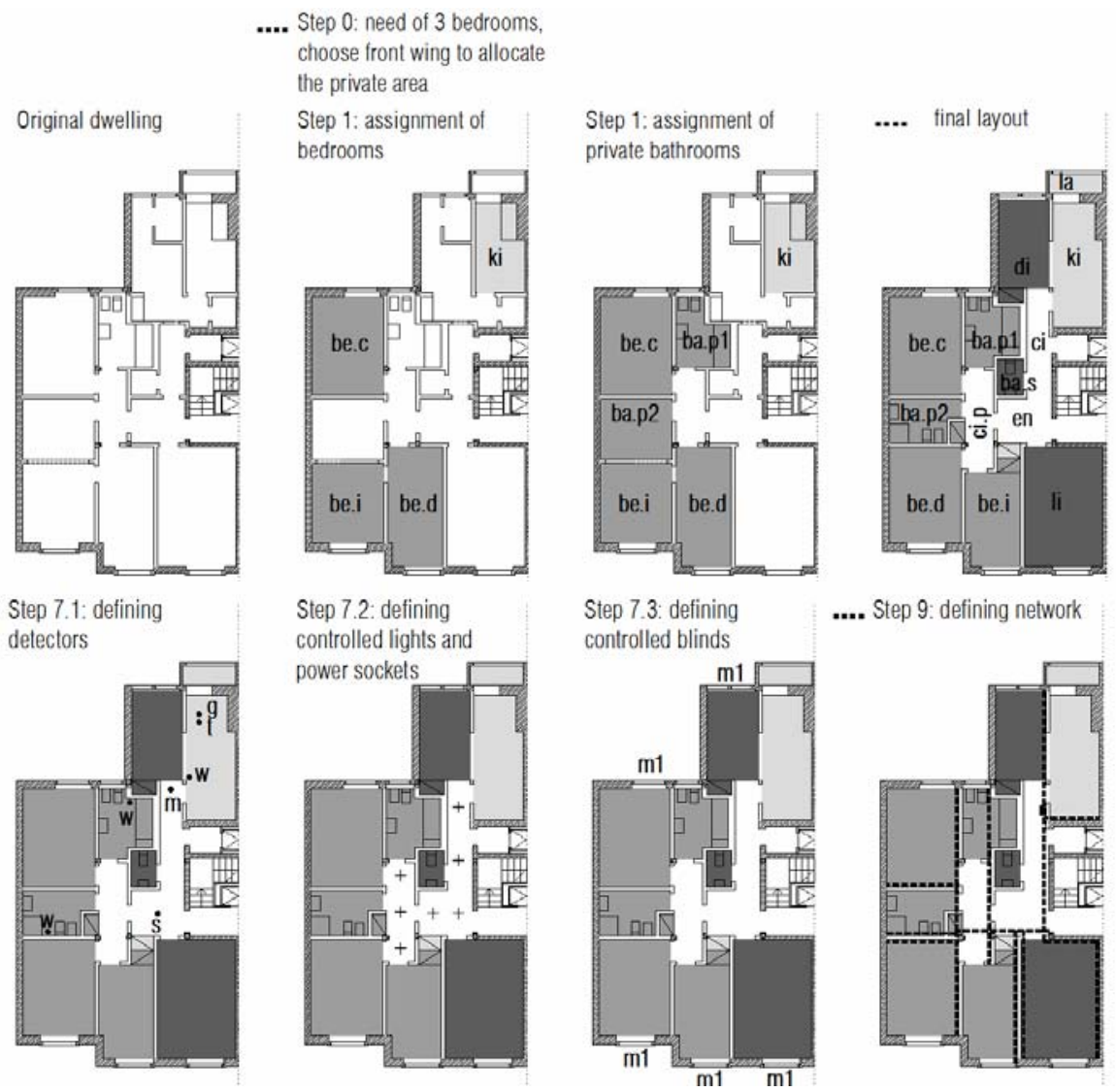

Fig. 2 - Partially derivation of one rehabilitation transformation

\section{Conclusion}

The incorporation of intelligent features adds value to homes and enhances the inhabitants' quality of live, while contributing to better housing management. Home automation technologies increases comfort in houses and helps inhabitants in daily domestic tasks promoting independency. This fact is of major importance to elderly and people with reduced mobility or other disabilities. In addition, the rehabilitation of Lisbon's existing housing stock is a priority in the political agenda and must fulfill new space-use requirements demanded by the new

The original publication is available at www.springerlink.com 
information age lifestyles as well as meet ecological, social, and economical sustainability.

In our research we propose strategies that permit to achieve an adequate balance between the tradeoffs involved in the rehabilitation of existing dwellings, the compliance with the new demands on housing functions and the integration of ICAT. The proposed methodology aims at supporting the adaptation of existing dwellings and the incorporation of ICAT according to user's real needs, promoting the development of ambient intelligence.

Currently we have already done some successfully experiments in which we were able to use grammar rules to transform dwellings both on functional aspects as well as introducing ICAT according to family profiles. Future work will be concerned with completing the transformation grammar and fine-tuning the relationship between the grammar rules and the integration of ICAT.

Acknowledgments. The research described in this paper project was funded by the Portuguese Science Foundation (FCT) with grant SFRH / BD / 18225 / 2004.

\section{References}

1. Aldrich, Frances K.2003. Smart Homes: Past, Present and Future. In Harper, Richard (ed.). 2003. Inside the smart home. London: Springer.

2. Becker Henk, Van de Goor. Anne-Geerte. 2001. Technology Generations in the Netherlands A Sociological Analysis. Shaker Publishers, Maastricht.

3. Bierhoff I, Berlo A van. 2007. Smart home Technology: on the move to ambient and invisible intelligence. In: Keijer U, Sandstrom G (ed). Smart Homes \& User Values. The Urban International Press, Great Britain, 45-67

4. Duarte J. P. 2001. Customizing Mass Housing: A Discursive Grammar for Siza's Malagueira houses. Thesis submitted to the Department of Architecture in Partial Fulfillment of the Requirements for the Degree of Doctor of Philosophy in Design and Computation. Massachusetts Institute of Technology, Cambridge, E.U.A.

5. Juez C S. 2007. La Realidad de un Sueňo. Vivenda domotizada para personas com discapacidad. Madrid: Asociación ADAMAR, Asociación DATO, DULCIT S.L.

6. INTEGER (s.d) INTEGER Intelligent \& Green. Tomorrow's Housing Today. Good Practice Guide

7. Mateas, M, Salvador, T, Scholtz, J and Sorensen, D. 1996. Engineering Ethnography in the Home, CHI 96 Electronic Proceedings.

8. Meyer, S and Schulze, E (1996) "The Smart Home in the 1990s. Acceptance and Future Usage in Private Households in Europe", in The Smart Home: Research Perspectives, The European Media Technology and Everyday Life Network (EMTEL), Working Paper No. 1, University of Sussex, Brighton.

9. Oliveira, F C A N. 2000. Os Novos Lugares do Habitar e as formas de apropriação contemporâneas. Lisboa: FAUTL. Master thesis - Arquitectura da Habitação.

10. Pedro, João Branco. 2000. Definição e avaliação da qualidade arquitectónica residencial. Lisboa: Faculdade de Arquitectura da Universidade do Porto. Thesis submitted for the Degree of Doctor of Architecture.

11. Stiny G, Gips J. 1972. Shape Grammars and the Generative Specification of Painting and Sculpture. C. V. Freiman, ed., Information Processing 71, North Holland, Amsterdam, 1460-1465 